\title{
Perceived gaps in early childhood development-related health policies in Iran: Findings from a qualitative exploratory study
}

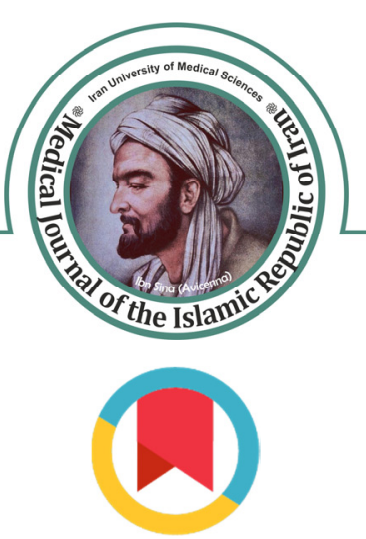

\section{Omolbanin Atashbahar ${ }^{1}$, Ali Akbari Sari*1, Amirhossein Takian ${ }^{1,2,3}$, Alireza Olyaeemanesh ${ }^{3,4}$, Sayyed Hamed Barakati}

Received: 23 Feb 2019

Published: 23 Dec 2019

\begin{abstract}
Background: Early childhood development (ECD) refers to physical, cognitive, emotional, and social development between 0 and 8 years. The aim of this study was to identify the gaps in ECD-related upstream and health policies in Iran.

Methods: This qualitative study consisted of 2 main methodologies. First, a document analysis of heath and upstream policies related to ECD in Iran was done. Second, following a purposive sampling approach, 24 semi-structured interviews were conducted with policymakers, managers, academics, and service providers in the field of children health from October 2017 until June 2018 in Tehran, Iran. Also, a mixed approach was used for content and thematic analysis of the data.

Results: In this study, 3 categories of gaps and weaknesses were found: (1) the inferior position of ECD in macro policies and lack of health considerations in upstream social development policies; (2) the imbalance approach to policymaking in health, lack of attention to removing inequalities, and centralized policymaking; (3) lack of effective ECD interventions and programs with regards to contextual considerations to improve children's development, and long-standing ignorance of developmental policies for 3-8 year-old children.

Conclusion: ECD is a fundamental policy approach for childhood development, which requires the policymakers' deep insight to shift their focus from physical development to combating the shortcomings in children's development cycle, eg, physical, mental, social, emotional, cognitive, and spiritual aspects. Unless policymakers change their approach to decrease nonintegrated and noncomprehensive policymaking for ECD, child development will be compromised, endangering the eventual sustainability of the society.
\end{abstract}

Keywords: Early childhood, Development, Health, Policy, Gaps, Weaknesses

Conflicts of Interest: None declared

Funding: Tehran University of Medical Sciences, Tehran, Iran

*This work has been published under CC BY-NC-SA 1.0 license.

Copyright $\subseteq$ Iran University of Medical Sciences

Cite this article as: Atashbahar O, Akbari Sari A, Takian A, Olyaeemanesh3 A, Barakati SH. Perceived gaps in early childhood development-related health policies in Iran: Findings from a qualitative exploratory study. Med J Islam Repub Iran. 2019 (23 Dec);33:146. https://doi.org/10.47176/mjiri.33.146

\section{Introduction}

ECD is often used to describe a range of programs that pursue a common ultimate goal, which is the realization of

\section{Corresponding author:Dr Ali Akbari Sari, akbarisari@tums.ac.ir}

1. Department of Health Management and Economics, School of Public Health, Tehran University of Medical Sciences, Tehran, Iran

2. Department of Global Health and Public Policy, School of Public Health, Tehran University of Medical Sciences, Tehran, Iran

3. Health Equity Research Centre (HERC), Tehran University of Medical Sciences, Tehran, Iran

4. National Institute for Health Research, Tehran University of Medical Sciences, Tehran, Iran

5. Population, Family and School Health Office, Ministry of Health and Medical Education, Tehran, Iran the potential capacities of children for optimal development. These programs may take place at different levels

\section{$\uparrow$ What is "already known” in this topic:}

There are different sporadic policies related to ECD in Iran and there are some barriers in various sectors that impede the optimal development of children.

\section{$\rightarrow$ What this article adds:}

For the first time in Iran, in this study, health sector policies were investigated from the perspective of ECD. Also, this study showed that there is a need for an integrated and comprehensive approach in policymaking for ECD. Emphasizing the importance of ECD in social development policies and tackling with existing inequalities were other important issues that need the due attention of the policymakers. 
(the child, the family, and the community) and among different sectors (health, care, education, and social support) (1). Early childhood is off icially considered the first 8 years of life based on the definition of the United $\mathrm{Na}$ tions Committee on the Rights of the Child (2). This is the most cost-effective stage of life to invest for the purpose of human development (3). Moreover, the most rapid period of brain development occurs in the first 2 years of life when critical neural pathways for social, emotional, and mental functions are designed (4). The high rate of return in investment in early childhood and recent progresses in neuroscience provide scientific background for reemphasis on the importance of ECD (5).

Among different sectors involved in ECD, the health sector plays a unique role compared to others, because it involves the first contact of the child and can be used as a gateway to other services in early childhood (6). Good access to mothers and children in this critical period, preventive services and screening tests, health and rehabilitation services for children with special needs, and use of health specialists in maternal education for better parenting are characteristics of the health sector (7). To be successful in this area, this sector requires appropriate policymaking more than anything else. Better policies and decisions will help to obtain better outcomes in children's health indicators, reduce inequity, and promote developmental outcomes (8).

In Iran, although important activities have been done in the field of children health in recent years, according to health experts and authorities, the current status of child development and its related activities are facing many challenges (9). Therefore, in 2008, for the first time, the Ministry of Health and Medical Education proposed to develop a national document for ECD. However, after developing this document for many years, it has not yet been implemented at a national level and is being implemented as a pilot. Hence, there are challenges in all sectors, including the health sector, but there are no related comprehensive and integrated policies to deal with these issues in the country. Thus, the aim of this study was to identify the existing weaknesses and gaps in the health and upstream policies related to ECD in Iran. To date, health policies and programs have not been studied from the perspective of ECD in Iran. The findings of the present study can contribute to the human capital development from early years and can strengthen ECD contribution to sustainable development.

\section{Methods}

\section{Study design and data collection}

In this qualitative exploratory study, 2 main methodologies were used: document analysis and interview. First, different search methods were used to identify and access ECD-related health policy documents. For this purpose, the websites of relevant organizations and agencies were reviewed. Personal and organizational communications were also used. In addition, upstream documents, such as the 20-Year Perspective Document for Iran, Constitution of the Islamic Republic of Iran, and development plans were considered. Finally, 39 national health policy docu- ments related to ECD and 10 upstream policy documents were analyzed. Then, face-to-face, semi-structured, indepth interviews were conducted. A generic interview guide was used to collect data in this phase (Appendix 1). The necessary information about the study and its purpose was provided to the participants, and their verbal informed consent was obtained prior to participation in the study. The participants were also assured of anonymity and confidentiality of their information. Interviews continued until data saturation. In total, 24 interviews were conducted, each of which lasting 30-90 minutes. These interviews were held in various locations based on the workplace of each interviewee from October 2017 until June 2018 in Tehran, Iran.

\section{Setting and sampling}

In the first phase of the study, all the identified documents were analyzed. In the second phase, the study population was policymakers and experts in the field of children health in Iran. Purposive sampling and snowball sampling were used to select the participants. Moreover, the participants had to have at least one of the following criteria: expertise in childhood development; neuroscience; health and nutrition; rehabilitation (preferably childoriented); at least 3 years of professional experience in the above fields in the public or nongovernmental sector; having a position related to children's affairs in the public or nongovernmental sector at the time of the study; and awareness of macro level policies in the fields related to children (Appendix 2).

\section{Data analysis}

For document analysis, a qualitative content analysis was performed using a checklist developed for this purpose. Thematic analysis was also applied. For this purpose, data collection and analysis were done simultaneously. After each interview, the audio-recorded interviews were transcribed verbatim. In fact, the researcher became familiar with the data during the process of listening to audio-recorded interviews, transcribing them, and reviewing handwritten notes. Then, quotes were extracted from a detailed summary of each interview and open coding was done. Next, the extracted codes were categorized into 3 categories. All steps were modified and approved by all authors. Finally, to ensure the accuracy of the interpretations of the data, the transcripts and categories were shared with the participants.

\section{Results}

Documents showed that the Ministry of Health and Medical Education designed appropriate plans and policies for survival and physical development of children, which reduced mortality and promoted the growth of children to a large extent.

The categorization of these policies and programs are presented in Table 1.

Identified gaps and weaknesses in studied policies: The main findings regarding gaps and weaknesses in the studied policies, which are categorized into 3 groups, are summarized in Table 2. 
Table 1. Categorization of identified policies

\begin{tabular}{|c|c|}
\hline Categories of policies & Identified policies \\
\hline Health coverage of population & - Health care network and facilities expansion \\
\hline Maternal health and nutrition & $\begin{array}{l}\text { - Designing a maternal mortality surveillance system } \\
\text { - Improving the safety of child birth in deprived and remote areas } \\
\text { - Family planning } \\
\text { - Establishing mother-friendly hospitals } \\
\text { - Nutritional consultations before and during pregnancy Nutritional support programs for poor pregnant } \\
\text { and lactating mothers with malnutrition }\end{array}$ \\
\hline Neonatal health and nutrition & $\begin{array}{l}\text { - Neonatal Resuscitation Program } \\
\text { - The Kangaroo Mother Care program } \\
\text { - Prenatal mortality reduction program } \\
\text { - Hypothyroidism screening program }\end{array}$ \\
\hline $\begin{array}{l}\text { Children under } 5 \text { years health and } \\
\text { nutrition }\end{array}$ & $\begin{array}{l}\text { - Integrated care for a healthy child (decreasing the risk of accidents, promoting breastfeeding, monitor- } \\
\text { ing growth and development, prevention of visual and auditory disorders, vaccination, providing nutri- } \\
\text { tional supplements, and referral if needed) } \\
\text { - Integrated pediatric illnesses care (standard control and treatment of communicable diseases) } \\
\text { - Designing an under } 5 \text { years mortality surveillance system } \\
\text { - Participatory and supportive program to improve the nutrition of disadvantaged children } \\
\text { - Providing one hot meal in the village kindergartens }\end{array}$ \\
\hline Upstream policies & $\begin{array}{l}\text { - The Constitution } \\
\text { - The 20-Year Perspective Document for Iran } \\
\text { - General policies of the Supreme Leader for health sector } \\
\text { - General policies of the Supreme Leader for family planning } \\
\text { - The Fourth, Fifth, and Sixth Development Plan Acts } \\
\text { - The establishment law of the Ministry of Health } \\
\text { - The law for the promotion of breastfeeding and mother protection } \\
\text { - The law authorizing the Government of the Islamic Republic of Iran to join to the Convention on the } \\
\text { Rights of the Child }\end{array}$ \\
\hline
\end{tabular}

Table 2. Identified weaknesses and gaps in the studied policies

\begin{tabular}{ll}
\hline Them & Identified Weaknesses and gaps \\
\hline Position of ECD in macro policies & - Inferior position of ECD in macro policies \\
& - Lack of health considerations in upstream social development policies \\
Policymaking approaches to health & - Imbalance in health policymaking \\
& - Inattention to removing inequalities \\
& - Centralized policymaking \\
Gaps in effective ECD interventions & - Lack of effective context-based promoting interventions and programs in ECD \\
and programs & - Lack of a context-based early interventions package to address cognitive, social, and emotional disor- \\
& ders \\
& - Long-standing ignorance of developmental policies for 3-8-year-old children
\end{tabular}

\section{Position of ECD in macro policies}

Inferior position of ECD in macro policies: One of the identified important issues in this study, which was frequently expressed by interviewees, was the lack of an explicit reference to children's issues in the upstream documents. It was argued that children's issues did not have a higher priority in the macro policies compared to other issues. In other words, ECD is not considered in the country's macro policies, especially development plans and children's position in these policies is not clearly identified.

"Current Iranian macro policies, including upstream policy documents and regulations, should explicitly express the position of children as members of the community. A general suggestion about issues related to children is not enough. Well, this shows that this area is not very important to us, compared to other issues in the country." (PM1).

"In our macro policies, practically in all development programs, you still do not see any trace of this issue, which I think is really a fundamental problem in our development programs." (ACA1).

Moreover, although it has been a good practice to in- clude ECD in the objectives of the health sector in the Sixth Development Plan, it would have been better to allocate an independent chapter to this topic or clearly discuss it to clear the roles and responsibilities of all involved sectors. A brief mention of ECD cannot indicate the importance of this issue in the country's Sixth Development Plan.

"Of course, it is a positive point to mention early childhood development in the Sixth Development Plan, but it has been mentioned as one of the objectives of the health sector. It would be better to assign a separate section to this issue so that roles and responsibilities of other sectors are clearly identified in this regard." (ACA2).

Lack of health considerations in upstream social development policies: Not considering health as an indicator of social development in macro policies of the country was another important issue. As a result, policies, plans, and projects in other sectors do not have health attachments and only the health sector is considered responsible for the community health and there is not a good intersectoral collaboration in health and ECD initiatives.

"We do not look at health as an indicator of social development. In our macro policies, we think that health is 
the task of a particular group and is produced in a certain way; as a result, social dimensions are neglected in this approach. When health is considered a public service, it means any activity can affect the community health, particularly children's health. So, any policy or program should have a health attachment." (PM2).

\section{Policymaking approaches to health}

Imbalance in policymaking: The results of this study showed that children-related health policies mainly focused on the reduction of mortality and morbidity rate and, in general, the physical development of children than mental, social-emotional, and spiritual aspects. Moreover, imbalanced policies and programs in the health sector were discussed by the interviewees as a weakness, leading to neglecting social determinants of health, health promotion, and preventive activities.

"Our health system policies mainly focus on the clinical practice and control of mortality and morbidity rates. Little attention has been paid to social determinants of health, including ECD and health promotional and preventive programs." (ACA3).

"We have succeeded to achieve a good survival and growth rate for our children, but we need to consider other developmental dimensions in our policies." (PM1).

\section{Inattention to removing inequalities}

The results of this study showed that the childhood health policies have an insignificant justice-oriented content and are less concerned about tackling inequalities. According to participants' opinions in this study, it is crucial to consider inequities in children health area at policymaking level.

"We do not pay attention to inequalities in our policies at all; eg, we only try to say whether or not we have promoted children's health while totally ignoring the distribution of our efforts." (HM1).

"Overall, there are significant improvements in child and maternal health, but this progress is related to the average of the whole community and vulnerable groups are not specifically considered." (PM3).

\section{Centralized policymaking}

Another finding in this study was the fact that the health system policies are highly concentrated. Regional differences and needs are not properly addressed. One of the reasons for the inequality in the indicators of child and maternal health in the different regions of the country is concentrated policymaking and lack of attention to regional differences.

"We need to develop provincial programs to improve the mortality rates and other indicators for children, infants, and pregnant women in different areas of the country and in line with ECD. I think we are very centralized in policymaking, which disregards regional differences and needs." (HM2).

\section{Gaps in effective ECD interventions and programs}

Lack of effective context based promoting interventions and programs in ECD: Lack of effective context-based interventions and programs to promote development of healthy children was another subject discussed in this study. Although these children do not have developmental disorders or delays, they do not necessarily have the best developmental conditions, and their developmental potential can be improved by promotional interventions and programs. Furthermore, there are concerns about the lack of attention to the context in the designed interventions and programs.

"If we have healthy children, we should provide the best conditions for their development. A healthy child in Iran does not necessarily have the best possible condition in terms of developmental growth. This can be improved by application of a series of interventions but we still lack such strategies. Therefore, we can say that our health policies and programs are not targeted at healthy children." (ACA4).

"Unfortunately, the parenting package that the Ministry of Health has received from our pediatric psychiatrist team is not a good one. It is a translation from other countries' plans, and, unfortunately, it is not applicable in the context of Iran." (PM4).

Lack of a context-based early interventions package to address cognitive, social, and emotional disorders

An identified gap in the field of developmental disorders was the lack of an early interventions package for cognitive and socio-emotional disorders at the country level. When diagnostic tests reveal that a child has a developmental delay or disorder, he/she should be referred to receive early interventions. This gap has been present for many years. Lack of standard intervention packages puzzle the therapists as to how to deal with a child at very young age.

"We have not defined an early intervention package for cognitive and socio-emotional disorders. In the area of motor and linguistic disorders, early interventions that have been designed are not implemented in the country. We are not sure whether a therapist to whom a 1-2-yearold is being referred knows what exactly to do." (HP1).

Long-standing ignorance of developmental policies for 3-8-year-old children

Another weakness identified in this study was the lack of an integrated program to promote the growth and development of 3-8-year-old children. These children are neglected in terms of development, because the rate of referring children to health centers decreases after 2 years of age. There are no programs and policies to target this group of children. This issue is particularly aggravated, as not all of these children are covered by child care services such as kindergartens or preschool programs, so it is difficult to access them.

"The Ministry of Health has considered more routine visits for vaccination and growth monitoring for children aged 0-2 years than other age groups. Contact with health centers reduces in other age groups and we have not designed proper programs for growth and development of 38 -year-old children. This is a very challenging issue since not all children in this age group are covered by kinder- 
gartens and preschool programs." (PM5).

\section{Discussion}

Due to improvements in survival and physical development, a window of opportunity is now open for the health system to focus more on other developmental aspects of children in ECD. Therefore, based on results of this study, health policies and programs require considering a number of points:

First, macro level public policies should focus on issues related to children and serve as a guide and facilitator for meso and micro policies. Policymakers should promote early equity by giving a higher priority to early childhood development in all policies. ECD has a large-scale positive effect on the community; hence, policymakers are advised to integrate ECD into agendas for public policies. These positive effects include social development, decreased health problems (eg, NCDs) high return rate of investment, and decreased costs of social welfare (10).

Second, health should be considered as an indicator of social development in macro policies. This point can be seen in the Helsinki Statement entitled "Health in All Policies". In this regard, health-based policies and regulations should be designed and implemented in all sectors. Moreover, the health effects of the existing policies and plans on the community, especially vulnerable populations such as children under 5 years and pregnant women, should be assessed. The aim of this approach is to enhance evidencebased policymaking and improve the awareness of policymakers by linking policies and interventions with health determinants and outcomes; therefore, the ultimate goal of this approach is to bridge the gap in health inequity. (11)

Third, health policies and programs should be comprehensive and underline social determinants of health, preventive and promotional activities, and all aspects of child development. Therefore, the WHO Commission on Social Determinants of Health in 2008 entitled "closing the gap in a generation" emphasized early childhood development and programs to consider various dimensions of child development, including physical, mental, socio-emotional and cognitive development (12). It is more cost-effective to work on ECD to improve the social determinants of health (2). Furthermore, health policies and programs in line with ECD should focus on preventive and promoting practices rather than clinical and therapeutic aspects. Slemming stated that this approach to ECD decreases costs, improves efficiency, and promotes health outcomes, especially for poor children (13).

Forth, health policies and programs should address inequities in children health. One of the basic principles of ECD programs is fair promotion of children's health and development. Therefore, ECD programs around the world, in addition to the child health, child care, and child education programs, have a supportive component (14). Kruk stated that redistributive health policies to promote the distribution of health services for the poor population may reduce the gap between the rich and the poor in under-5 mortality rate in low- and middle-income countries. Therefore, essential health services for children should clearly target poor children. Although governmental health expenditure has been associated with a reduction in overall mortality rates at the national level, it has not had any impact on justice in mortality outcomes (15). Furthermore, the Lancet papers have shown that interventions targeting the poorest children can provide a huge return on investment (16).

Fifth, health policies and programs should be flexible. Mirzoev et al emphasized that contextual differences should be considered in health policymaking. This study exemplified India and Nigeria in this regard and stated that although health policymaking is often centralized at the national level in both countries, there is enough flexibility in the local level to develop their own unique health policies (17).

Sixth, health policies and programs should consider cost-effective and context specific strategies to promote the development of healthy children, especially children aged 3-8 years. This group needs special attention, because there is a need for strategies that improve these children' access to health care services. Children' access to high quality care services as a right can undoubtedly help children achieve their maximum developmental potential. These services can be provided in various forms, including family-based child care, center-based child care, in-home relative care, and home-visiting programs. The quality of these services is the element that matters the most and should be continuously promoted (18). Moreover, although there is a great emphasis on the importance of context in developmental science, it is not sufficiently considered in translation efforts. Existing evidence in this area, in addition to considering the potential of interventions in training of social, cognitive and parenting skills, has also addressed the existing problems in transferring these interventions to a specific context. Therefore, it is recommended that developmental scientists begin with their own specific context of the community (19).

Seventh, health policies and programs should produce an effective and standard early interventions package to address developmental delays or disorders. A large body of evidence shows that despite the sensitivity and vulnerability of the brain to early deficiencies, initial interventions often create significant improvements in brain functions and have more benefits. Allen stated that, unfortunately, in the UK, children care interventions in the social, emotional, and mental areas are too late until the problems become serious (20).

Limitations: This study was done for the first time in Iran and no studies have investigated health sector policies and programs from the perspective of early childhood development. However, this study had 3 main limitations. First, policies in other sectors were not considered and we only focused on health and upstream policies. Second, we focused on content analysis of these policies and existed challenges in policy process were not considered. Third, some participants were not able to participate in the confirmation process because of their busy schedule and the lack of time.

\section{Conclusion}

ECD is a fundamental policy approach to childhood de- 
velopment and addresses which policy requires widening policy makers' insight and understanding to enhance their focus from physical development and mortality reduction towards combating the existing inequalities and shortcomings about children's development cycle. Some examples are physical, mental, socioemotional, cognitive, and spiritual aspects. Policymakers are required to emphasize the social determinants of health and preventive and promotional programs for ECD. Furthermore, policymakers should have a special commitment to providing equal opportunities for optimal development of all children in public policies and do not consider it an unnecessary or lowpriority subject, compared to other community subjects, as community problems are rooted in early years of life. Unless policymakers change their approach to decrease nonintegrated and noncomprehensive policymaking for ECD, child development will be compromised, which may eventually endanger the sustainable society of Iran.

\section{Acknowledgements}

This paper has been extracted from a $\mathrm{PhD}$ thesis supported by Tehran University of Medical Sciences, Tehran, Iran. The authors highly appreciate the contribution of participants.

\section{Conflict of Interests}

The authors declare that they have no competing interests.

\section{References}

1. World Health Organization and UNICEF. Early childhood development and disability: A discussion paper. World Health Organization and UNICEF; 2012.

2. Woodhead M, Bolton L, Featherstone I, Robertson P. Early childhood development: delivering intersectoral policies, programs and services in low resource settings. The health \& education advice \& resource team (HEART); 2014.

3. Barnett WS. The Economic Case: Effective Early Childhood Programmes. Milton Keynes: The Open University; 2009. http://bernardvanleer.org.

4. AvanB I, Kirkwood BR. Review of the theoretical frameworks for the study of child development within public health and epidemiology. J Epidemiol Community Health. 2010; 64:388e393.

5. Sayre RK, Devercelli AE, Neuman MJ, Wodon Q. Investing in early childhood development: review of the world bank's recent experience. International Bank for Reconstruction and Development; 2015.

6. Soudee AR. Incorporating indigenous knowledge and practice into ECCE: a comparison of programs in the Gambia, Senegal and Mali. Curr Issues Comp Educ. 2009;11:15-23.

7. World Health Organization and UNICEF. Role of the health sector in promoting early childhood development: A strategic framework. WHO/UNICEF; 2011.

8. Davids M, Samuels ML, September R, Moeng TL, Richter L, Mabogoane TW, et al. The pilot evaluation for the National Evaluation System in South Africa - A diagnostic review of early childhood development. Afr Evaluat J. 2015;3(1).

9. Vameghi R, Marandi A, Sajedi F, Soleymani F, Shahshahanipour S, Hatamizadeh N. Strategic analysis of the situation in Iran regarding the development of young children (analysis swot) and proposed strategies and activities. Soc Welfare Quart. 2010; 9(35):379-412. (Persian)

10. The World Bank Group, the Inter-American Development Bank and UNICEF. G20 development working group :Investing in early childhood development. This discussion document was created in support of the Presidency of the Argentine Government for the 2018 G20. The World Bank Group, the Inter-American Development Bank and UNICEF; 2018.
11. Leppo K, Ollila E, Peña S, Wismar M, Cook S. Health in all policies: seizing opportunities, implementing policies. Ministry of social affairs and health, Finland; 2013.

12. World Health Organization. Closing the gap in a generation (Health equity through action on the social determinants of health). World Health Organization, commission on social determinants of health; 2008.

13. Slemming W, Saloojee H. Beyond survival: The role of health care in promoting ECD. South African Child Gauge; 2013.

14. The National ECD Secretariat. National integrated early childhood development policy of Uganda. Ministry of Gender, Labour and Social Development; 2016.

15. Kruk ME, Prescott MR, Pinho H, Galea S. Equity and the child health millennium development goal: the role of pro-poor health policies. J Epidemiol Community Health. 2011; 65:327-333.

16. Lake A. Early childhood development - global action is overdue. Lancet. 2011; 378.

17. Mirzoev T, Das M, Ebenso B, Uzochukwu B, Rawat B, Blok L, et al. Contextual influences on the role of evidence in health policy development: what can we learn from six policies in India and Nigeria? Evid Policy. 2015; 13(1):59-79.

18. National association for the education of young children website. http://www.naeyc.org. Accessed November 9, 2016.

19. Dodge KA. Context Matters in Child and Family Policy. Child Dev. 2011 Jan-Feb;82(1):433-42.

20. Allen MPG. Early Intervention: The Next Steps. An Independent Report to Her Majesty's Government. H M Government; 2011. 
Appendix A:

Interview guide

1. What are the health policies and programs in the country for the early childhood development of children? (Any program or policy that aims at improving the capacity of children to develop and learn at different levels, such as the child, family and society)

2. What do you think about the content of health policies and programs relevant to optimal child development? Has a good targeting been done?

3. In your opinion, what are the weaknesses and gaps in health policies relevant to ECD?

4. In your opinion, what factors should be considered in health policy in order to improve child development?

5. Have children's issues been properly addressed in the macro policies and upstream documents of the country?

6. Has the subject of early childhood development been addressed in the macro policies and upstream documents of the country?

7. Do issues related to children have a higher priority than other community issues in national policymaking?

8. Is there any further subject you would like to add?

Appendix B:

Table 1. Demographic characteristics of interviewees

\begin{tabular}{|c|c|c|c|}
\hline Variable & & Vumber & Percent \\
\hline \multirow[t]{2}{*}{ Gender } & Male & 14 & $58.33 \%$ \\
\hline & Female & 10 & $41.66 \%$ \\
\hline \multirow[t]{10}{*}{ specialty } & Management and health policy & 5 & $20.83 \%$ \\
\hline & Pediatrics & 5 & $20.83 \%$ \\
\hline & Health education & 2 & $8.33 \%$ \\
\hline & General medicine & 2 & $8.33 \%$ \\
\hline & Neuroscience & 2 & $8.33 \%$ \\
\hline & Pregnancy health & 1 & $4.16 \%$ \\
\hline & Epidemiology & 2 & $8.33 \%$ \\
\hline & Social work & 2 & $8.33 \%$ \\
\hline & Nutrition & 2 & $8.33 \%$ \\
\hline & Social medicine & 1 & $4.16 \%$ \\
\hline \multirow{4}{*}{ Position } & Policymaker (PM) & 10 & $41.66 \%$ \\
\hline & Health manager (HM) & 5 & $20.83 \%$ \\
\hline & Academic (ACA) & 7 & $29.16 \%$ \\
\hline & Health Provider (HP) & 2 & $8.33 \%$ \\
\hline \multirow[t]{5}{*}{ Organization } & Children's Medical Center & 2 & $8.33 \%$ \\
\hline & $\begin{array}{l}\text { Ministry of Health and Medical Education, including Pediatric Department, Department } \\
\text { of Social Assistance, and Department of Community Nutrition Improvement } \\
\text { Social welfare Organization } \\
\text { Universities and research centers }\end{array}$ & 9 & $37.50 \%$ \\
\hline & Committees and associations, including Iranian Pediatrics & 4 & $16.66 \%$ \\
\hline & Association and Neonatal Development Committee & 7 & $29.16 \%$ \\
\hline & & 2 & $8.33 \%$ \\
\hline \multirow[t]{2}{*}{ Education } & PH.D & 15 & $62.50 \%$ \\
\hline & $\mathrm{MD}$ & 9 & $37.50 \%$ \\
\hline
\end{tabular}

